\title{
Estrogen and Progesterone Replacement Therapy Reduces Low Density Lipoprotein Accumulation in the Coronary Arteries of Surgically Postmenopausal Cynomolgus Monkeys
}

\author{
Janice D. Wagner, Thomas B. Clarkson, Richard W. St. Clair, Dawn C. Schwenke, Carol A. Shively, and Michael R. Adams \\ Arteriosclerosis Research Center and Comparative Medicine Clinical Research Center, Bowman Gray School of Medicine, \\ Wake Forest University, Winston-Salem, North Carolina 27157
}

\begin{abstract}
The effect of estrogen and progesterone replacement therapy on the initiating events in atherogenesis was studied in surgically postmenopausal cynomolgus monkeys. Monkeys were ovariectomized and divided randomly into two groups, one receiving $17 \beta$-estradiol and cyclic progesterone treatment $(n=9)$ and ovariectomized controls receiving no hormone replacement therapy $(n=8)$. The monkeys were fed a moderately atherogenic diet for 18 wk to accelerate the early pathogenic processes but not to be of sufficient duration to produce grossly visible atherosclerotic lesions. Sex hormone replacement therapy decreased the accumulation of LDL and products of LDL degradation in the coronary arteries by $>70 \%$ while having no significant effect on plasma lipid, lipoprotein, or apoprotein concentrations. Arterial intimal lesions were small with no difference between groups. The reduction in arterial LDL metabolism occurred very early in the pathogenesis of atherosclerosis and was independent of indices of endothelial cell injury, such as enhanced endothelial cell turnover or leukocyte adhesion to the endothelium. Results of this study suggest that one mechanism by which sex hormone treatment inhibits the initiation of atherosclerosis is a direct effect at the level of the arterial wall by suppressing the uptake and/or degradation of LDL. ( $J$. Clin. Invest. 1991. 88:1995-2002.) Key words: atherosclerosis - sex hormones • lipoproteins • menopause • endothelium
\end{abstract}

\section{Introduction}

Although coronary heart disease is more prevalent in men than women, it remains the leading cause of death in women in Western societies (1). Both natural and surgical menopause are associated with accelerated development of coronary artery atherosclerosis and the clinical expression of coronary heart disease, and among postmenopausal women, estrogen replacement therapy has been shown to decrease the risk of coronary

A portion of this paper was presented at the 62 nd Scientific Sessions of the American Heart Association, 13-16 November 1989 (1989. Circulation. 80[Suppl. II]: II-331 [Abstr.]).

Address correspondence and reprint requests to Janice D. Wagner, D.V.M., Department of Comparative Medicine, Bowman Gray School of Medicine, Medical Center Boulevard, Winston-Salem, NC 271571040.

Received for publication 19 November 1990 and in revised form 01 August 1991.

J. Clin. Invest.

(C) The American Society for Clinical Investigation, Inc.

0021-9738/91/12/1995/08 $\$ 2.00$

Volume 88, December 1991, 1995-2002 heart disease $(2,3)$. Taken together, these observations suggest a protective effect of estrogen on the pathogenesis of coronary artery atherosclerosis and the occurrence of coronary heart disease.

The Lipid Research Clinics Program Follow-up Study (3) found that the cardiovascular mortality in estrogen users was about one-third of that of nonusers. After statistical adjustment for risk factors (blood pressure, smoking, and age), Bush et al. (3) determined that about half of the protective effect of estrogen use was accounted for by estrogen-induced increases in high density lipoprotein cholesterol (HDLC) ${ }^{1}$ and decreases in low density lipoprotein (LDL) cholesterol concentrations. Thus, half of the protective effect of estrogen use must be mediated by mechanisms other than its effects on plasma LDL and HDL cholesterol concentrations.

The purpose of this study was to investigate the influence of sex hormone therapy on early atherogenic processes in cynomolgus monkeys. In another animal model of atherogenesis, the hypercholesterolemic rabbit, increases in the arterial concentration of undegraded LDL and arterial rates of LDL degradation appear to be early events in the pathogenesis of atherosclerosis (4); these aspects of the interaction of LDL with the arterial wall are exaggerated once atherosclerotic lesions are present $(5,6)$. Thus, to study the influence of sex hormones on atherogenesis, this study was designed to assess metabolic effects (accumulation of LDL and its degradation within the artery) and cellular events (intimal proliferation, leukocyte adhesion to the arterial wall, and endothelial cell turnover) that are believed to occur before the formation of grossly detectable atherosclerotic lesions.

The cynomolgus monkey was chosen for this study because females of this species have a menstrual cycle similar to that of human females (7-9), and female cynomolgus monkeys, like human females, develop less coronary artery atherosclerosis than their male counterparts $(10,11)$. This effect has been shown to be influenced by the estrogenic state of the monkey (10-12). Females that are ovariectomized have estradiol concentrations similar to males and more extensive atherosclerosis than intact females, while pregnancy and the resultant increase in plasma estradiol concentrations is associated with decreased atherosclerosis (12). Also, we have shown recently that hormone replacement therapy results in a decreased extent of coronary artery atherosclerosis in surgically postmenopausal monkeys (13). We report here that sex hormone replacement mark-

1. Abbreviations used in this paper: ANCOVA, analysis of covariance; ANOVA, analysis of variance; FCR, fractional catabolic rate; HDLC, high density lipoprotein cholesterol; LAD, left anterior descending; LCX, left circumflex; TC, tyramine cellobiose; TPC, total plasma cholesterol. 
edly suppresses the accumulation of ${ }^{125}$ I-tyramine cellobiose (TC)-LDL in the coronary arteries, as determined by the arterial content of ${ }^{125} \mathrm{I}-\mathrm{TC}$ which reflects undegraded $\mathrm{LDL}$ and products of LDL degradation, without affecting other indices of atherogenesis including endothelial cell proliferation and leukocyte adhesion to the endothelium.

\section{Methods}

Animal study. 17 adult female cynomolgus monkeys (Macaca fascicularis) of Indonesian origin were obtained from Charles River Research Primates (Port Washington, NY). The animals averaged $7.0 \pm 0.5 \mathrm{yr}$ of age (mean \pm SEM) as estimated by dentition. After a 3-mo quarantine period during which the animals were fed Monkey Chow (Ralston Purina Co., St. Louis, MO), they were randomized into two groups. Two animals, one from each group, entered the protocol each month. The experimental period was $18 \mathrm{wk}$ during which the monkeys consumed a moderately atherogenic diet containing $40 \%$ of calories as fat and 0.25 $\mathrm{mg}$ cholesterol per kilocalorie (13). Based on past experience, the 18-wk period of cholesterol feeding was selected to accelerate the early pathogenic processes in the development of atherosclerosis, but not to be of sufficient duration to produce grossly visible atherosclerotic lesions. All procedures involving animals were conducted in compliance with state and federal laws, standards of the Department of Health and Human Services, and guidelines established by the Institutional Animal Care and Use Committee. Surgical procedures (ovariectomy and arterial catheterization) were performed while the animals were anesthetized with ketamine hydrochloride $(10 \mathrm{mg} / \mathrm{kg} \mathrm{i.m}$.) and butorphanol tartrate $(0.05 \mathrm{mg} / \mathrm{kg}$ i.m.), whereas minor procedures (blood sampling and implant manipulations) were performed while the animals were sedated with ketamine hydrochloride $(15 \mathrm{mg} / \mathrm{kg}$ i.m.).

Hormone manipulations. The experimental period began $3 \mathrm{wk}$ after ovariectomy. Estrogen and progesterone replacement therapy was accomplished by means of silastic implants (Dow Corning Corp., Midland, MI) that were placed subcutaneously between scapulae (13). In the treatment group, physiologic sex hormone concentrations were maintained using two implants, one containing $17 \beta$-estradiol and one containing progesterone. Estrogen implants remained in place continuously while progesterone implants were inserted for the last $2 \mathrm{wk}$ out of each $4 \mathrm{wk}$ to approximate discrete follicular and luteal phases as well as the combined estrogen-progestin therapy commonly prescribed for postmenopausal women. Ovariectomized controls, not receiving hormone replacement therapy, received empty implants inserted on a similar schedule. Plasma progesterone and estradiol concentrations were assayed at weeks 4,12 , and 16 by radioimmunoassay utilizing antisera which have been characterized for use in monkeys $(14,15)$. These samples were taken at the end of the $2 \mathrm{wk}$ with progesterone implants.

Plasma lipids and lipoproteins. Blood samples were collected into EDTA $(1 \mathrm{mg} / \mathrm{ml}$ final concentration) after the animals were fasted overnight. Determinations were made of total plasma cholesterol (TPC), triglycerides, $\mathrm{HDLC}$, and $\mathrm{HDL}$ subfractions 2 and $3\left(\mathrm{HDL}_{2}\right.$ and $\mathrm{HDL}_{3}$ ) at baseline (before ovariectomy, experimental diet, and hormone manipulations) and 2, 4, 6, 10,12, and $18 \mathrm{wk}$. LDL cholesterol was estimated from total plasma cholesterol and HDLC concentrations (16). TPC and triglycerides were measured by automated enzymatic procedures. The cholesterol procedure is based on the method of Allain et al. (17), while the triglyceride procedure is based on the method of Fossati and Prencipe (18). Plasma HDLC was determined by the heparin-manganese precipitation procedure as described in the Manual of Laboratory Operations of the Lipid Research Clinics Program (19). The differential dextran sulfate precipitation method of Gidez et al. (20) was used to determine $\mathrm{HDL}_{2}$ and $\mathrm{HDL}_{3}$ cholesterol concentrations. Analyses for TPC, triglyceride, and HDLC are in full standardization with the CDC-NHLBI Lipid Standardization Program. LDL molecular weight $(21,22)$, and apoproteins (apo) A1 (23) and B (24) were determined once at baseline, and at weeks 8 and 14 .
Isolation and labeling of $L D L$. To isolate autologous $\mathrm{LDL}$, blood samples $(20 \mathrm{ml})$ were collected at weeks 14 and 15 after the animals were fasted overnight. The LDL was isolated by combined ultracentrifugation and agarose column chromatography as described previously $(25,26)$. The only modification of this method was that $0.02 \%$ sodium azide was mixed with the blood for bacteriostasis and was removed by dialysis before injection into the monkeys. Approximately 8-12 mg of LDL protein, as measured by the method of Lowry (27), were isolated from each animal.

One aliquot (6.4-9.6 $\mathrm{mg}$ ) of each LDL preparation was coupled to ${ }^{125}$ I-tyramine cellobiose (TC), as described previously $(28,29)$. A second aliquot (1.6-2.4 mg) of each LDL preparation was labeled with ${ }^{131} \mathrm{I}$ using the iodine monochloride method $(30)$ as described previously (25). Specific activities of the ${ }^{125} \mathrm{I}-\mathrm{TC}-\mathrm{LDL}$ and ${ }^{131} \mathrm{I}-\mathrm{LDL}$ averaged $251 \pm 66$ and $67 \pm 18 \mathrm{cpm} / \mathrm{ng}$ protein, respectively (mean \pm SEM) for 17 preparations. For ${ }^{125} \mathrm{I}-\mathrm{TC}-\mathrm{LDL}$ and ${ }^{131} \mathrm{I}$-LDL, TCA-soluble radioactivities (10\% final concentration) averaged $10 \pm 4 \%$ and $4 \pm 1.5 \%$ and radioactivities extractable in chloroform/methanol (31) averaged $4 \pm 0.5 \%$ and $8 \pm 3 \%$, respectively. Just before injection, the two aliquots of each LDL preparation were combined and sterilized by filtration $(0.45 \mu \mathrm{m})$. LDLs were used within $1 \mathrm{wk}$ of labeling.

In vivo studies. After $18 \mathrm{wk}$ of consuming the atherogenic diet, radiolabeled LDLs were injected into each animal and the animal was necropsied $24 \mathrm{~h}$ later. To facilitate the studies with labeled LDLs, indwelling femoral venous and arterial catheters were inserted. Each monkey was then fitted with a nylon mesh jacket and attached to a flexible metal tether (Alice King Chatham Medical Arts, Los Angeles, CA) in its cage (32). The labeled LDL $\left(5.60 \pm 1.29 \times 10^{7} \mathrm{cpm}{ }^{131} \mathrm{I}\right.$ and $1.33 \pm 0.33 \times 10^{9} \mathrm{cpm}^{125}$ I) were injected through the venous catheter 1 $\mathrm{d}$ after inserting the catheters. Subsequent blood samples were collected in EDTA ( $0.1 \%$ final concentration) from the arterial catheter at 5,15 , 30 , and $60 \mathrm{~min}$ and $3,7,13$, and $24 \mathrm{~h}$ after injection to determine the plasma decay of labeled LDL.

To label replicating endothelial cells, we injected the animals intravenously with ${ }^{3} \mathrm{H}$-thymidine at a dose of $0.5 \mathrm{mCi} / \mathrm{kg}$ body weight per injection at three time points (17, 9, and $1 \mathrm{~h}$ before necropsy) (33).

Necropsy and measurement of atherosclerosis. The animals were necropsied immediately after the last blood sample was collected for the plasma decay of LDL. The animals were anesthetized with sodium pentobarbital $(60 \mathrm{mg} / \mathrm{kg}$ body weight, i.v.), and were perfused with lactated Ringer's solution through catheters introduced into the left ventricle. An incision was made in the vena cava through which blood containing labeled LDL and perfusate were removed. When the vena caval effluent became colorless, the perfusate was changed to a modified Karnovsky's fixative (29). After perfusing for $5 \mathrm{~min}$, the vena cava was clamped and pressure was maintained at $100 \mathrm{mmHg}$ for an additional $15 \mathrm{~min}$ to provide adequate fixation for electron microscopy and radiolabeled $\mathrm{LDL}$.

The heart was removed and the left anterior descending (LAD) and left circumflex (LCX) coronary arteries were dissected free. Adventitia was removed and the arteries were fixed in modified Karnovsky's fixative for $24 \mathrm{~h}$. Segments were taken as shown in Fig. 1 for histologic and electron microscopic study and for studies of the interaction of radiolabeled LDL with the artery.

One section ( $5 \mu \mathrm{m}$ ) was taken from each paraffin block (segment $A$, Fig. 1) and stained with Verhoeff-van Gieson (34). The sections were projected and intimal thickness was measured at 4-mm intervals with a digitizer (35). The extent of coronary artery atherosclerosis was expressed as the mean intimal thickness (millimeters).

Segments (segment $B$, Fig. 1) were also prepared for scanning electron microscopy as described previously (33). 200 fields $\left(0.006 \mathrm{~mm}^{2}\right.$ each) were examined at a magnification of 1,250 using a Philips 501 scanning electron microscope. Endothelial cell turnover rates were expressed as number of labeled nuclei per square millimeter of endothelial surface observed. Although the radiolabeled LDL contributed to cellular radiographic grains, this label was easily distinguished due to its more uniform cytoplasmic distribution as opposed to the nuclear location of ${ }^{3} \mathrm{H}$-thymidine. The number of adherent leukocytes (identified 


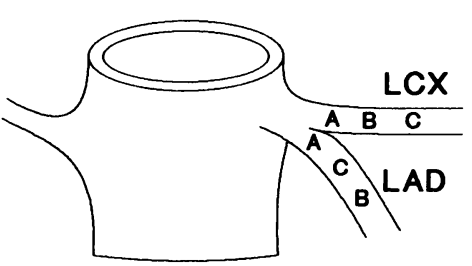

Figure 1. Segments from the left circumflex $(L C X)$ and left anterior descending $(L A D)$ coronary arteries were evaluated. Segment $A$ was prepared for light microscopy, segment $B$ for scanning electron microscopy, and segment $C$ for the interaction of $\mathrm{LDL}$ with the arterial wall.

as cells between 8 and $15 \mu \mathrm{m}$ in diameter) was also determined in segment $B$ and results are reported as number of cells per square $\mathrm{mm}$.

Finally, the interaction of LDL with the coronary arteries was evaluated (segment $C$, Fig. 1). ${ }^{125}$ I and ${ }^{131}$ I radioactivity in arterial tissues and plasma were determined in a well-type gamma counter (model 5500B; Beckman Instruments, Inc., Fullerton, CA). Both total ${ }^{125}$ I and ${ }^{131}$ I radioactivity in plasma and the fraction of plasma radioactivity that was protein bound (as determined by TCA precipitable radioactivity, $10 \%$ final concentration) were determined. Arterial samples, LAD and LCX, averaged ( \pm SEM) $12.2 \pm 1.6 \mathrm{mg}$ and $12.1 \pm 2.0 \mathrm{mg}$, respectively, with no difference between groups. Radioactivities in all samples were corrected for overlap of the energy spectra of the two isotopes, for background radioactivity and for isotopic decay. Arterial samples were counted for $\sim \mathbf{4 0}$ min for each isotope during which an average of $169,739 \pm 52,754$ gross counts of ${ }^{125} I$ and $6,585 \pm 793$ gross counts of ${ }^{131} I$ accumulated, giving a 2 Sigma counting error of $<0.5 \%$ for ${ }^{125} \mathrm{I}$ and $<3.0 \%$ for ${ }^{131}$ I. Background was counted until a minimum of 10,000 counts accumulated resulting in a 2 Sigma counting error of $<2 \%$. The coefficient of variation on net counts per minute for ${ }^{125} \mathrm{I}$ present in arterial samples was $0.9 \pm 0.1 \%$. For approximately one-fourth of the arterial samples, no net ${ }^{131}$ I radioactivity could be detected. For the remaining samples, the coefficient of variation on net counts per minute for the ${ }^{131}$ I present was $11.8 \pm 3.0 \%$. Because the ${ }^{131}$ I present in arterial samples was too low to be determined accurately, arterial ${ }^{131}$ I data will not be presented.

Analysis of $L D L$ studies. Clearance of LDL from plasma was determined from the decay of protein-bound radioactivity in the plasma during the $24 \mathrm{~h}$ from injection of labeled LDL until death. Data for the plasma decay of protein-bound radioactivity of each monkey were fitted with biexponential equations using a nonlinear regression algorithm (BMDP Statistical Software, Los Angeles, CA). The fractional catabolic rate (FCR) of LDL was determined from the rate constants and coefficients defined by the biexponential fit to the radioactive decay in the plasma (36). Similarly, the fraction of the dose irreversibly degraded at the time of death was calculated from the decay of ${ }^{125}$ I-TCLDL in plasma $(4,29,37)$.

At the end of the experiment, coronary arteries were fixed in a modified (half-strength) Karnovsky's fixative (29). Fixation in this manner preserves both products of ${ }^{125}$ I-TC-LDL degradation trapped in lysosomes and undegraded ${ }^{125}$ I-TC-LDL that has either not yet been taken up by arterial cells or is within cells but has not yet been degraded $(28,29)$. Thus, for tissues fixed in this manner, radioactivity from ${ }^{125} \mathrm{I}-$ TC represents both undegraded LDL and products of arterial LDL degradation. The arterial ${ }^{125} \mathrm{I}-\mathrm{TC}$ radioactivity (counts per minute per gram) was normalized by the average protein-bound plasma ${ }^{125} \mathrm{I}-\mathrm{TC}$ radioactivity during the metabolic experiment to express the arterial ${ }^{125} \mathrm{I}-\mathrm{TC}$ radioactivity in a form (nanoliters per gram per hour) which is independent of the plasma LDL concentration and the dose of LDL that was injected. The average plasma ${ }^{125}$ I-TC radioactivity ([cpm/ $\mathrm{nl}] * \mathrm{~h}$ ) was determined from the area under the plasma decay curve (38). If a sufficient amount of ${ }^{131}$ I radioactivity had accumulated in the arteries, this would have allowed us to determine the amount of undegraded LDL present and then calculate rates of LDL degradation after correcting for the amount of arterial ${ }^{125} \mathrm{I}-\mathrm{TC}$ representing undegraded LDL. Because there was not enough ${ }^{131}$ I radioactivity to obtain an accurate estimate of undegraded LDL, we report here only data for ${ }^{125}$ I-TC, which represents the sum of undegraded LDL and LDL degradation products.

Statistical analysis. Data for arterial morphology were analyzed after square root transformation while lipid, lipoprotein, and apoprotein concentrations and arterial ${ }^{125}$ I-TC accumulation were analyzed after logarithmic transformation to reduce skewness and equalize group variances. Variables measured during the baseline period (body weight, lipids, lipoproteins, and apoproteins) that significantly predicted the outcome measures were identified by multiple regression and used in group comparisons as covariates to reduce the variability in outcome measures by accounting for variability in pretreatment factors. Statistical comparisons between treatment groups were made by analysis of variance (ANOVA) and covariance (ANCOVA). However, results of analyses were similar whether or not pretreatment variables were included. Analyses were performed with the BMDP statistical package (BMDP Statistical Software, Los Angeles, CA). Means presented in the text are reported with the SEM. Comparisons resulting in $P \leq 0.05$ were considered significantly different.

\section{Results}

Reproductive steroids. Ovariectomized controls without hormone replacement had undetectable levels of plasma estradiol $(<20 \mathrm{pg} / \mathrm{ml})$ and very low concentrations of plasma progesterone $(0.29 \pm 0.03 \mathrm{ng} / \mathrm{ml})$. In contrast, animals receiving estrogen and progesterone replacement therapy had physiologic concentrations of both $17 \beta$-estradiol $(124 \pm 29 \mathrm{pg} / \mathrm{ml})$ and progesterone $(5.4 \pm 0.3 \mathrm{ng} / \mathrm{ml} ; P<0.001$ for both estradiol and progesterone concentrations, control vs. hormone replacement).

Plasma lipoproteins. Baseline plasma lipid, lipoprotein, and apoprotein measures were compared between groups to determine whether there were differences before treatment ( $\mathrm{Ta}-$ ble I). Although there were small (nonsignificant) differences between groups in several of the variables at baseline, by random chance apo A1 was significantly different $(P<0.05)$. To account for variability in pretreatment values, we performed all statistical analyses using baseline variables as covariates. As shown in Table $I$, the atherogenic diet produced a moderate hypercholesterolemia in both groups. Hormone therapy did not produce a significant change in plasma lipid and lipoprotein concentrations except for LDL molecular weight $(P$ $<0.05$ ). Due to the possibility that LDL of different molecular weights would be metabolized at a different rate than the animal's own LDL, autologous LDL was used for the studies of the interaction of LDL with the artery.

Plasma decay kinetics. Fractional catabolic rates of LDL, determined from the plasma decay curves for ${ }^{125} \mathrm{I}-\mathrm{TC}-\mathrm{LDL}$ and ${ }^{131} \mathrm{I}-\mathrm{LDL}$, were not significantly different $(0.054 \pm 0.005$ vs. $0.063 \pm 0.006$ pools $\mathrm{h}^{-1},{ }^{125} \mathrm{I}-\mathrm{TC}-\mathrm{LDL}$ vs. ${ }^{131} \mathrm{I}-\mathrm{LDL}, P=0.27$ ), indicating that type of radiolabel did not influence the rate of plasma clearance (see Fig. 2 for representative decay curve). Fractional catabolic rates were not affected by hormone treatment $\left(0.052 \pm 0.008\right.$ vs. $0.056 \pm 0.008$ pools $\mathrm{h}^{-1},{ }^{125} \mathrm{I}-\mathrm{TC}-\mathrm{LDL}$, control vs. hormone treated, $P=0.71)$. Consistent with that observation, monkeys in both groups degraded similar fractions of the injected dose $\left(0.56 \pm 0.04\right.$ vs. $0.58 \pm 0.04,{ }^{125} \mathrm{I}-\mathrm{TC}$ LDL, control vs. hormone treated, $P=0.70$ ).

Arterial accumulation of ${ }^{125} I-T C$. Preliminary analyses revealed that when treatment effects on the LAD and LCX were considered together in a repeated measures analysis, no significant differences between arteries were found $(P>0.62)$, thus, subsequent analyses were done using the mean of these two 


\begin{tabular}{|c|c|c|c|c|}
\hline & \multicolumn{2}{|c|}{$\begin{array}{l}\text { Control } \\
(n=8)\end{array}$} & \multicolumn{2}{|c|}{$\begin{array}{l}\text { Hormone replacement } \\
\qquad(n=9)\end{array}$} \\
\hline & Baseline & Treatment & Baseline & Treatment \\
\hline Total plasma cholesterol (TPC) $(m g / d l)$ & $127 \pm 7$ & $383 \pm 30$ & $138 \pm 6$ & $341 \pm 30$ \\
\hline HDL cholesterol (HDLC) $(m g / d l)$ & $61 \pm 4$ & $52 \pm 5$ & $71 \pm 6$ & $71 \pm 11$ \\
\hline $\mathrm{HDL}_{2}$ subfraction $(m g / d l)$ & $36 \pm 3$ & $25 \pm 3$ & $46 \pm 5$ & $46 \pm 9$ \\
\hline $\mathrm{HDL}_{3}$ subfraction $(m g / d l)$ & $25 \pm 2$ & $29 \pm 3$ & $25 \pm 2$ & $27 \pm 3$ \\
\hline TPC:HDLC & $2.2 \pm 0.2$ & $9.8 \pm 1.5$ & $2.0 \pm 0.2$ & $8.2 \pm 2.0$ \\
\hline LDL cholesterol (TPC-HDLC) $(m g / d l)$ & $66 \pm 7$ & $331 \pm 33$ & $67 \pm 3$ & $270 \pm 32$ \\
\hline Triglyceride $(m g / d l)$ & $38 \pm 4$ & $28 \pm 5$ & $46 \pm 6$ & $43 \pm 7$ \\
\hline Apoprotein Al $(m g / d l)$ & $166 \pm 9^{*}$ & $149 \pm 13$ & $240 \pm 28$ & $210 \pm 28$ \\
\hline Apoprotein B $(m g / d l)$ & $99 \pm 16$ & $175 \pm 12$ & $89 \pm 8$ & $160 \pm 17$ \\
\hline LDL molecular weight $(\mathrm{g} / \mu \mathrm{mol})$ & $3.23 \pm 0.12$ & $3.35 \pm 0.03^{*}$ & $3.28 \pm 0.11$ & $3.21 \pm 0.07$ \\
\hline Body weight $(\mathrm{kg})$ & $3.54 \pm 0.24$ & $3.38 \pm 0.20$ & $3.64 \pm 0.16$ & $3.51 \pm 0.16$ \\
\hline
\end{tabular}

Values are means \pm SEM. Baseline values were determined before cholesterol feeding, ovariectomy, and hormone manipulations. Statistical analyses were performed after logarithmic transformation. Treatment values were determined at multiple times during the experimental protocol; for controls (atherogenic diet with ovariectomy alone) or hormone replacement (ovariectomy with estrogen and progesterone replacement). Statistical analyses were performed after logarithmic transformation with baseline variables as covariates. ${ }^{*} P<0.05$ for control vs. hormone replacement.

arteries. Multiple regression analysis revealed that no pretreatment (baseline) characteristics were significant predictors of LDL accumulation; therefore effects of hormone replacement were analyzed using ANOVA. The principal finding of these studies was that the combined accumulation of products of LDL degradation and undegraded LDL in the arterial tissue $\left({ }^{125} \mathrm{I}-\mathrm{TC}\right.$ accumulation) was more than threefold greater in animals not receiving hormone replacement (Table II).

Histologic and ultrastructural analysis. The effects of hormone therapy on intimal thickness, endothelial cell turnover, and the number of adherent leukocytes on the arterial wall were examined. Preliminary analyses revealed that when treatment effects on the LAD and LCX were considered together in a repeated measures analysis, no significant differences between arteries were found (all $P$ values $>0.52$ ). Thus, all subsequent analyses were done using the combined mean of these two arteries.

Multiple regression was used to determine which pretreatment (baseline) characteristics of the animals were significant predictors of outcome measures. Pretreatment values of $\mathrm{HDL}_{2}$

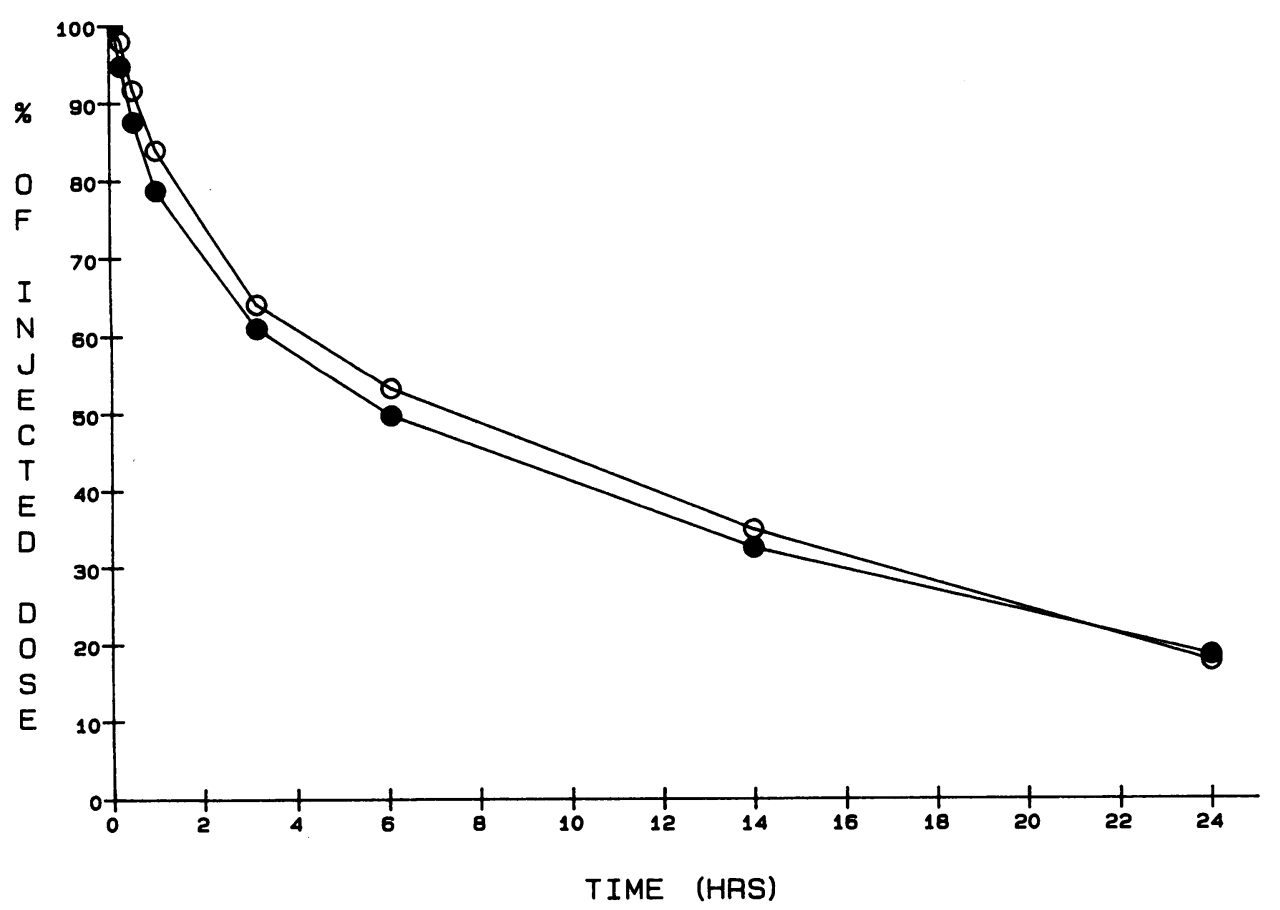

Figure 2. Representative plasma decay curve for ${ }^{125}$ I-TC-LDL (solid circles) and ${ }^{131}$ I-LDL (open circles). Monkey 2530 was injected with 5.34 $\times 10^{8} \mathrm{cpm}^{125} \mathrm{I}$-TC-LDL and 6.16 $\times 10^{7} \mathrm{cpm}{ }^{131} \mathrm{I}$-LDL. Data were fitted with biexponential equations using a nonlinear regression algorithm. Fractional catabolic rates (FCR) were determined as described in Methods. FCRs for ${ }^{125}$ I-TC-LDL and ${ }^{131} \mathrm{I}-\mathrm{LDL}$ were 0.079 and 0.077 pools/h, respectively. 
Table II. Effect of Hormone Treatment on Accumulation of ${ }^{125} \mathrm{I}$ TC and Morphologic Characteristics of Coronary Arteries

\begin{tabular}{lccc}
\hline & $\begin{array}{c}\text { Control } \\
(n=8)\end{array}$ & $\begin{array}{c}\text { Hormone } \\
\text { replacement } \\
(n=9)\end{array}$ & $P$ \\
\hline $\begin{array}{l}\text { Accumulation of }{ }^{125} \mathrm{I}-\mathrm{TC} \\
(\mathrm{nl} / \mathrm{g} / \mathrm{h})^{*}\end{array}$ & $5954 \pm 2612$ & $1753 \pm 479$ & 0.04 \\
$\begin{array}{l}\text { Intimal thickness }\left(\mathrm{mm}^{2}\right)^{\ddagger} \\
\text { Endothelial cell turnover }\end{array}$ & $0.006 \pm 0.002$ & $0.007 \pm 0.003$ & 0.60 \\
$\quad$ rate $\left(\mathrm{cells} / \mathrm{mm}^{2}\right)^{\ddagger}$ & $0.47 \pm 0.23$ & $0.79 \pm 0.46$ & 0.69 \\
Adherent cells $\left(\mathrm{cells} / \mathrm{mm}^{2}\right)^{*}$ & $2.9 \pm 0.7$ & $2.5 \pm 0.5$ & 0.80 \\
& & & \\
\hline
\end{tabular}

Values are means \pm SEM

* Statistical analyses were performed by ANOVA after transformation. ‡ Statistical analyses were performed by ANCOVA after transformation.

accounted for $29 \%$ of the variance in mean intimal thickness and pretreatment values of plasma triglyceride concentrations, $\mathrm{HDL}_{2}$ concentrations, and the TPC:HDLC ratio together accounted for $53 \%$ of the variance in endothelial cell turnover rates. No pretreatment variables significantly predicted the number of adherent leukocytes. The effects of treatment on endothelial cell turnover and adherent leukocytes were then analyzed by ANCOVA, using significant baseline predictors as covariates.

Hormone therapy over this 18 -wk period did not have a significant effect on intimal thickness, endothelial cell turnover rate, or the number of adherent leukocytes (Table II). The intimal lesions produced by the moderate hypercholesterolemia of 4 mo duration were very small and did not differ in thickness between groups. A photomicrograph of a typical coronary artery is shown in Fig. 3. Although most of the intima appeared normal, small focal accumulations of foam cells and small areas of diffuse intimal thickening were observed in some histologic sections. The endothelial cell turnover rates and the number of adherent cells were also small, suggesting limited amounts of endothelial injury. Thus, the changes produced with this degree and duration of hypercholesterolemia were mild with no difference between groups in any of the morphologic measurements examined.

\section{Discussion}

This study was designed to investigate the effects of estrogen and cyclic progesterone replacement therapy on atherogenesis in surgically postmenopausal monkeys. Events which may play a role in initiating atherogenesis, such as the uptake and accumulation of LDL by the arterial wall, endothelial cell damage, and adherence of leukocytes to the endothelium were evaluated. Because we were interested in the early events in the pathogenesis of atherosclerosis, monkeys were studied after a short period of moderate hypercholesterolemia and, therefore, before the appearance of grossly visible atherosclerotic lesions (Fig. 3). This is particularly important for studies of LDL interaction with the arterial wall because rates of LDL degradation are markedly enhanced when atherosclerotic lesions are present $(5,6)$.

Effects of hormone therapy on atherogenesis may be mediated, at least in part, by plasma lipoprotein concentrations and composition. The effects of sex hormones on plasma lipoprotein distribution have been studied extensively. Premenopausal women $(2,3)$ and monkeys $(10,12)$ typically have lower plasma LDL cholesterol concentrations and higher HDLC concentrations than males of similar age. The difference in $\mathrm{HDLC}$ is principally in the $\mathrm{HDL}_{2}$ subfraction, the fraction most strongly associated (negatively) with coronary artery atherosclerosis $(2,3)$. In the present study, the lack of a significant effect of hormone therapy on plasma lipids and lipoproteins, despite trends in the expected directions (Table I), may relate to the short period of study, the limited number of animals available for study, or the potency and route of administration of the hormones.

The route of administration has been shown to affect changes in plasma lipids (see reference 2 for review). In general, whereas both oral and parenteral treatments increase circulat-

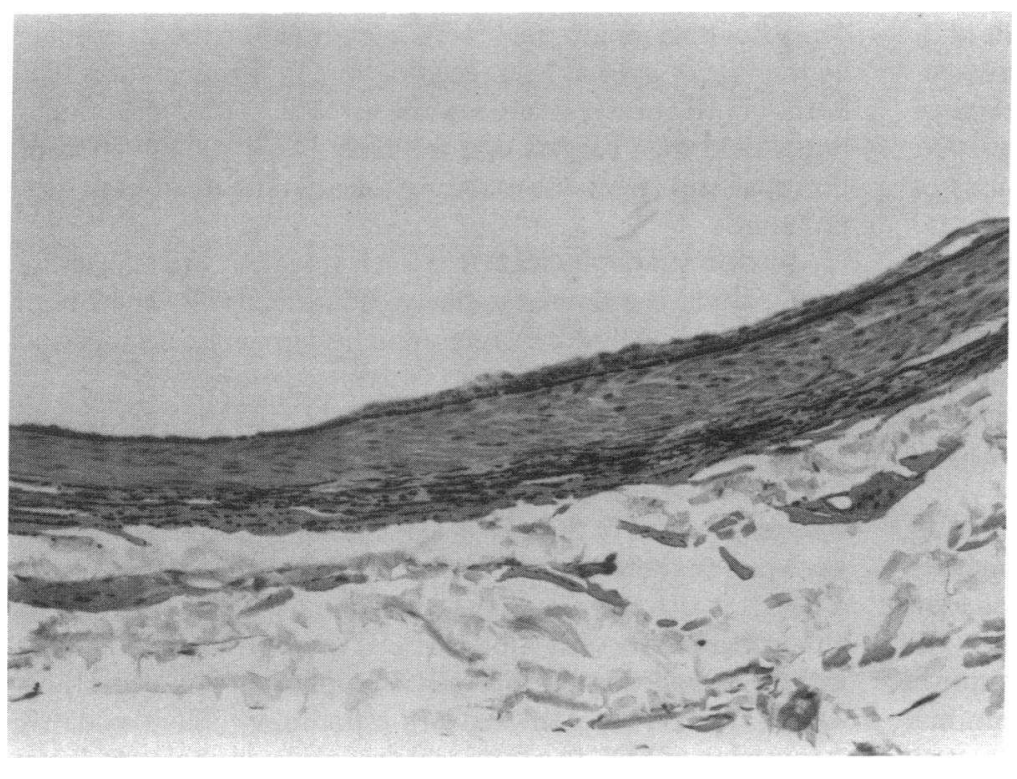

Figure 3. Photomicrograph of a portion of a typical Verhoef van Gieson-stained section of a coronary artery after $18 \mathrm{wk}$ of a moderately atherogenic diet. The majority of the intimal surface appeared normal histologically except for a.small intimal thickening shown here which involved $\sim 10 \%$ of the intimal surface. Magnification, 200. 
ing estradiol concentrations to a similar degree, in the study of Basdevant et al. (39) only oral treatment reduced LDL cholesterol, and in the study of Fahraeus et al. (40) only oral treatment increased HDLC concentrations. It is possible that treatments that also improve lipoprotein patterns may be even more effective in inhibiting development of atherosclerosis. However, other studies in rabbits (41) and monkeys (13) have found inhibitory effects of estrogen on atherosclerotic lesion development despite no effect on plasma lipoproteins. Using a hormone replacement method identical to the one described here, Adams et al. (13) found that after $30 \mathrm{mo}$, animals treated with either estrogen alone or estrogen plus progesterone had significantly less diet-induced coronary artery atherosclerosis than ovariectomized controls. Furthermore, the antiatherogenic effects of hormone replacement were independent of changes in plasma cholesterol, lipoprotein cholesterol, apo A1 and $B$ concentrations, HDL subfraction heterogeneity and LDL molecular weight (13). This suggests that estrogen with or without added progesterone may have a protective effect on the development of atherosclerosis that is independent of its effects on plasma lipoproteins and that in the present study, the addition of progesterone may not have affected atherogenesis.

Differences in LDL molecular size may have important pathophysiologic implications because LDL size and particle heterogeneity are important predictors of coronary artery atherosclerosis and coronary heart disease in nonhuman primates (42). Parks et al. (43) found that treatment with the oral contraceptive Demulen (ethinyl estradiol and ethynodiol diacetate) decreased the LDL molecular weight significantly. However, in the study by Adams et al. (13), effects of hormone replacement therapy on LDL molecular weight were small and transitory. Because the study by Adams et al. (13) was similar in design to the present study, except for a longer experimental period, this suggests that any effects of hormone replacement therapy on LDL molecular weight may be insignificant over longer periods of time. However, we cannot discount the possibility that the interaction of LDL with the arterial wall may be influenced by subtle differences in LDL particle composition and heterogeneity induced by hormone replacement. Hormone treatment may also influence the expression of LDL receptors in the arterial wall. An estrogen-induced increase in LDL receptors has been seen in rat liver (44-46) and in swine granulosa cells (47). Eriksson (48) has reported that in human beings, a pharmacologic dose of ethinyl estradiol increased the fractional clearance rate of $\mathrm{LDL}$, presumably secondary to upregulation of $\mathrm{LDL}$ receptors. In our study, where physiologic concentrations of estradiol and progesterone were coadministered, there was no effect on the clearance of LDL from plasma, suggesting that at these concentrations there is no enhancement of LDL receptor activity. This suggests that in this study, the effects of sex hormones on the accumulation and/or degradation of LDL by the arterial wall is probably not secondary to alterations in LDL receptor function, but rather suggests an independent effect of estrogen and/or progesterone on the artery.

Because of the brief duration of the atherogenic stimulus, there was no grossly visible atherosclerosis and intimal changes in the coronary artery (intimal thickness, number of adherent leukocytes, or endothelial cell turnover rate) were minimal (Table II). As shown in the photomicrograph (Fig. 3), the amount of microscopically visible changes in the intima were minimal with no differences between groups (Table II). Clarkson et al.
(33) found an endothelial cell turnover rate of $\sim 0.6$ cells/ $\mathrm{mm}^{2}$ in the coronary arteries of control monkeys fed a nonatherogenic diet, whereas monkeys fed an atherogenic diet for 35 wk exhibited about a sixfold higher turnover rate. The values obtained in the present study are comparable to the control values reported in the earlier study (33), suggesting that the 18 wk of moderate hypercholesterolemia in the current experiment did not damage endothelial cells enough to stimulate cell proliferation. The number of adherent leukocytes, generally $80 \%$ monocytes (49), was also low and comparable to that found by Clarkson et al. (33) for the coronary arteries of control monkeys. Thus, the effect of hormone replacement on LDL accumulation and/or degradation occurred before any differences in these other indices of endothelial cell dysfunction.

Hough and Zilversmit (41) investigated the effects of estrogen treatment (17-estradiol cypionate) of cholesterol-fed rabbits on net arterial influx and hydrolysis of plasma cholesteryl ester entering the artery. Despite no significant effect on plasma cholesterol concentrations or lipoprotein patterns, estrogen treatment decreased lesion development significantly. In each group, net cholesteryl ester influx was positively correlated with the extent of atherosclerosis while the percentage of newly entering cholesteryl ester hydrolyzed by the artery was independent of the extent of atherosclerosis. When normalized by aortic cholesterol, net influx of plasma cholesteryl ester did not differ between estrogen-treated and untreated rabbits. In contrast, the percentage of newly entered cholesteryl ester hydrolyzed by the artery was suppressed by estrogen treatment; this effect was evident whether or not differences in aortic cholesterol were considered.

In the present study we had intended to determine directly the arterial rate of degradation of LDL protein. Unfortunately, due to the insufficient ${ }^{131} I$ radioactivity in the artery of some animals, we were not able to obtain reliable estimates of the portion of the arterial ${ }^{125} \mathrm{I}$-TC accumulation representing undegraded LDL with which to correct the total arterial ${ }^{125} \mathrm{I}-\mathrm{TC}$ accumulation for all animals. However, in the monkeys for which the coefficient of variation of the net arterial ${ }^{131} \mathrm{I}$ radioactivity was $10 \%$ or less, $\sim 60 \%$ of the ${ }^{125}$ I-TC accumulation represented products of arterial LDL degradation; there was no significant difference between treated and untreated animals. Thus, our data for arterial ${ }^{125} \mathrm{I}$-TC accumulation reflect primarily the rate of arterial LDL degradation. Our observation that hormone treatment decreased the arterial ${ }^{125} \mathrm{I}-\mathrm{TC}$ accumulation would then suggest that the most likely site of action of hormone treatment was to reduce the arterial rate of LDL degradation.

In vitro studies indicate that after uptake by cells the entire LDL particle is delivered to the lysosome as a unit, where both protein and cholesteryl ester moieties undergo degradation (50). Therefore, both the report that estrogen decreases hydrolysis of cholesterol ester by rabbit artery (41) and the present data for ${ }^{125} \mathrm{I}$-TC accumulation support the conclusion that estrogen treatment inhibits the catabolism of LDL by the arterial wall. The mechanism of this effect is unclear. Estrogens could influence one or more of the intracellular steps in the processing of LDL. It is also possible that sex hormone deficiency promotes the intraarterial conversion of LDL to a form which is more rapidly degraded by arterial cells. In support of this idea, Huber et al. (51) have reported that $17 \beta$-estradiol inhibited oxidative conversion of LDL to a form which stimulated cholesteryl ester 
accumulation in macrophages. Alternatively, it may be that subtle differences in LDL composition induced by hormone deficiency increase degradation by the artery. Further studies will be needed to sort out these possible explanations for the decrease in arterial LDL accumulation associated with estrogen/progesterone replacement.

In summary, sex hormone replacement therapy decreased the ${ }^{125} \mathrm{I}-\mathrm{TC}$ accumulation by coronary arteries by $>70 \%$ while having no significant effect on plasma lipids, coronary artery endothelial cell turnover, or leukocyte adhesion. Our data suggest that suppression of the accumulation and/or degradation of LDL may be an important mechanism by which natural or surgical menopause exacerbate atherosclerosis. This study further suggests that changes in LDL metabolism by the arterial wall can occur very early in the pathogenesis of atherosclerosis and independent of changes in endothelial cell function associated with endothelial cell injury, such as enhanced turnover rate or leukocyte adhesion.

\section{Acknowledgments}

The authors would like to thank Dr. Steve Adelman for the preparation of the tyramine cellobiose, Mr. Wynn Fitzpatrick for assisting in the labeling of LDL, Ms. Maryanne Post, Ms. Chris Kneppelt, and Mr. Tom Byers for assisting in the histologic and electron microscopic analyses.

This study was supported in part by SCOR in Arteriosclerosis grant HL14164 from the National Heart Lung and Blood Institute and grant T32RR07009 from the National Institutes of Health.

\section{References}

1. Eaker, E. D., B. Packard, N. K. Wenger, T. B. Clarkson, and H. A. Tyroler. 1987. Coronary Heart Disease in Women. Haymarket Doyma, Inc., New York. 267-270.

2. Godsland, I. F., V. Wynn, D. Crook, and N. E. Miller. 1987. Sex, plasma lipoproteins, and atherosclerosis: prevailing assumptions and outstanding questions. Am. Heart J. 114:1467-1503.

3. Bush, T. L., E. Barrett-Connor, L. D. Cowan, M. H. Criqui, R. B. Wallace, C. M. Suchindran, H. A. Tyroler, and B. M. Rifkind. 1987. Cardiovascular mortality and noncontraceptive use of estrogen in women: results from the Lipid Research Clinics Program Follow-up Study. Circulation. 75:1 102-1109.

4. Schwenke, D. C., and T. E. Carew. 1989. Initiation of atherosclerotic lesions in cholesterol-fed rabbits. I. Focal increases in arterial LDL concentration precede development of fatty streak lesions. Arteriosclerosis. 9:895-907.

5. Carew, T. E., D. C. Schwenke, and D. Steinberg. 1987. Antiatherogenic effect of probucol unrelated to its hypocholesterolemic effect: evidence that antioxidants in vivo can selectively inhibit low density lipoprotein degradation in macrophage-rich fatty streaks and slow the progression of atherosclerosis in the Watanabe heritable hyperlipidemic rabbit. Proc. Natl. Acad. Sci. USA. 84:77257729.

6. Schwenke, D. C., and T. E. Carew. 1987. Determination of LDL degradation rate, content, and residence time in lesioned and nonlesioned aorta. Circulation. 76(Suppl. IV):313. (Abstr.)

7. MacDonald, G. T. 1971. Reproductive patterns of three species of macaques. Fertil. Steril. 22:373-377.

8. Jewett, D. A., and W. R. Dukelow. 1972. Cyclicity and gestation length of Macaca fascicularis. Primates. 13:327-330.

9. Williams, R. F., and G. D. Hodgen. 1982. The reproductive cycle in female macaques. Am. J. Primatol. 1(Suppl.):181-192.

10. Hamm, T. E., J. R. Kaplan, T. B. Clarkson, and B. C. Bullock. 1983 Effects of gender and social behavior on the development of coronary artery atherosclerosis in cynomolgus monkeys. Atherosclerosis. 221:48-57.

11. Kaplan, J. R., M. R. Adams, T. B. Clarkson, and D. R. Koritnik. 1984. Psychosocial influences on female "protection" among cynomolgus macaques. Atherosclerosis. 53:283-295.

12. Adams, M. R., J. R. Kaplan, T. B. Clarkson, and D. R. Koritnik. 1985. Ovariectomy, social status, and atherosclerosis in cynomolgus monkeys. Arteriosclerosis. 5:192-200.

13. Adams, M. R., J. R. Kaplan, S. B. Manuck, D. R. Koritnik, J. S. Parks,
M. S. Wolfe, and T. B. Clarkson. 1990. Inhibition of coronary artery atherosclerosis by 17-beta estradiol in ovariectomized monkeys. Lack of an effect of adding progesterone. Arteriosclerosis. 10:1051-1057.

14. Cronin, M. J., and D. R. Koritnik. 1983. Dopamine receptors of the monkey anterior pituitary in various endocrine states. Endocrinology. 112:618623.

15. Adams, M. R., J. R. Kaplan, and D. R. Koritnik. 1985. Psychosocial influences on ovarian endocrine and ovulatory function in cynomolgus monkeys (Macaca fascicularis). Physiol. Behav. 35:935-940.

16. Parks, J. S., J. Kaduck-Sawyer, B. C. Bullock, and L. L. Rudel. 1990. Effect of dietary fish oil on coronary artery and aortic atherosclerosis in african green monkeys. Arteriosclerosis. 10:1102-1112.

17. Allain, C. C., L. S. Poon, C. S. G. Chan, W. Richmond, and P. C. Fu. 1974. Enzymatic determination of total serum cholesterol. Clin. Chem. 20:470-475.

18. Fossati, P., and L. Prencipe. 1982. Serum triglycerides determined colorimetrically with an enzyme that produces hydrogen peroxide. Clin. Chem. 28:2077-2080.

19. Lipid Research Clinic Program, National Heart, Lung, and Blood Institute. 1974. (revised 1982). Manual of Laboratory Operations. Vol. 1. Lipid and Lipoprotein Analysis. National Institutes of Health, Bethesda, MD. DHEW publication No. 75-628.

20. Gidez, L. I., G. J. Miller, M. Burstein, S. Slagle, and H. A. Eder. 1982. Separation and quantitation of subclasses of human high density lipoproteins by a simple precipitation procedure. J. Lipid Res. 23:1206-1223.

21. Carroll, R. M., and L. L. Rudel. 1983. Lipoprotein separation and low density lipoprotein molecular weight determination using high performance gelfiltration chromatography. J. Lipid Res. 24:200-207.

22. Rudel, L. L., J. A. Lee, M. D. Morris, and J. M. Felts. 1974. Characterization of plasma lipoproteins separated and purified by agarose column chromatography. Biochem. J. 139:89-95.

23. Koritnik, D. R., and L. L. Rudel. 1983. Measurement of apolipoprotein A-I concentration in nonhuman primate serum by enzyme-linked immunosorbent assay (ELISA). J. Lipid Res. 24:1639-1645.

24. Sorci-Thomas, M., M. D. Wilson, F. L. Johnson, D. L. Williams, and L. L Rudel. 1989. Studies on the expression of genes encoding apolipoproteins B100 and B48 and the low density lipoprotein receptor in nonhuman primates. J. Biol. Chem. 264:9039-9045.

25. St. Clair, R. W., J. J. Mitschelen, and M. A. Leight. 1980. Metabolism by cells in culture of low-density lipoproteins of abnormal composition from nonhuman primates with diet-induced hypercholesterolemia. Biochim. Biophys. Acta. 618:63-79.

26. St. Clair, R. W., and M. A. Leight. 1983. Cholesterol efflux from cells enriched with cholesteryl esters by incubation with hypercholesterolemic monkey low density lipoprotein. J. Lipid Res. 24:183-191.

27. Lowry, O. H., N. J. Rosenbrough, A. L. Farr, and R. J. Randall. 1951. Protein measurement with the Folin phenol reagent. J. Biol. Chem. 193:265-275.

28. Pittman, R. C., T. E. Carew, C. K. Glass, S. R. Green, C. A. Taylor, Jr., and A. D. Attie. 1983. A radioiodinated, intracellularly trapped ligand for determining the sites of plasma protein degradation in vivo. Biochem. J. 212:791-800

29. Carew, T. C., R. C. Pittman, E. R. Marchand, and D. Steinberg 1984. Measurement in vivo of irreversible degradation of low density lipoprotein in the rabbit aorta. Predominance of intimal degradation. Arteriosclerosis. 4:214-224.

30. Bilheimer, D. W., S. Eisenberg, and R. I. Levy. 1972. The metabolism of very low density lipoprotein proteins. I. Preliminary in vitro and in vivo observations. Biochim. Biophys. Acta. 260:212-221.

31. Bligh, E. G., and W. J. Dyer. 1959. A rapid method of total lipid extraction and purification. Can. J. Biochem. Physiol. 37:911-917.

32. Adams, M. R., J. R. Kaplan, S. B. Manuck, B. Uberseder, and K. T Larkin. 1988. Persistent sympathetic nervous system arousal associated with tethering in cynomolgus macaques. Lab. Anim. Sci. 38:279-281.

33. Clarkson, T. B., D. M. Lombardi, N. J. Alexander, and J. C. Lewis. 1986. Diet and vasectomy: effects on atherogenesis in cynomolgus macaques. Exp. Mol. Pathol. 44:29-49.

34. Carson, F. L., S. A. Coleman, and H. N. Futch. 1987. Connective tissue and muscle fiber stains. In Theory and Practice of Histotechnology. B. Hrapchak and D. Sheehan, editors. Columbus, OH, Battelle Press. 196-197.

35. Clarkson, T. B., M. G. Bond, C. A. Marzetta, and B. C. Bullock. 1980. Approaches to the study of atherosclerosis regression in rhesus monkeys: interpretation of morphometric measurements of coronary arteries. In Proceedings of the Fifth International Symposium on Atherosclerosis. A. Gotto, Jr., L. Smith and B. Allen, editors. Springer-Verlag, New York. 739-748.

36. Yedgar, S., T. E. Carew, R. C. Pittman, W. F. Beltz, and D. Steinberg. 1983. Tissue sites of catabolism of albumin in rabbits. Am. J. Physiol. 144:E101E107.

37. Schwenke, D. C., and T. E. Carew. 1988. Quantification in vivo of increased LDL content and rate of LDL degradation in the normal rabbit aorta occurring at sites susceptible to early atherosclerotic lesions. Circ. Res. 62:699710 .

38. Schwenke, D. C., and D. B. Zilversmit. 1989. The arterial barrier to lipo- 
protein influx in the hypercholesterolemic rabbit. 2. Long-term studies in deendothelialized and reendothelialized aortas. Atherosclerosis. 77:105-115.

39. Basdevant, A., B. DeLigmeres, and B. Guy-Grand. 1983. Differential lipemic and hormonal responses to oral and parenteral 17 beta-estradiol in postmenopausal women. Am. J. Obstet. Gynecol. 147:77-81.

40. Fahraeus, L., and L. Wallentin. 1983. High density lipoprotein subfractions during oral and cutaneous administration of 17 beta estradiol to menopausal women. J. Clin. Endocrinol. \& Metab. 56:797-801.

41. Hough, J. L., and D. B. Zilversmit. 1986. Effect of 17 beta estradiol on cholesterol content and metabolism in cholesterol-fed rabbits. Arteriosclerosis. 6:57-63.

42. Rudel, L. L., M. G. Bond, and B. C. Bullock. 1985. LDL heterogeneity and atherosclerosis in nonhuman primates. Ann. NY Acad. Sci. 454:248-253.

43. Parks, J. S., S. J. Pelkey, J. Babiak, and T. B. Clarkson. 1989. Contraceptive steroid effects on lipids and lipoproteins in cynomolgus monkeys. Arteriosclerosis. 9:261-268.

44. Chao, Y.-S., E. E. Windler, G. C. Chen, and R. J. Havel. 1979. Hepatic catabolism of rat and human lipoproteins in rats treated with $17 \alpha$-ethinyl estradiol. J. Biol. Chem. 254:11360-11366.

45. Kovanen, P. T., M. S. Brown, and J. L. Goldstein. 1979. Increased binding of low density lipoprotein to liver membranes from rats treated with $17 \alpha$-ethinyl estradiol. J. Biol. Chem. 254:11367-11373.

46. Windler, E. E. T., P. T. Kovanen, Y.-S. Chao, M. S. Brown, R. J. Havel, and J. L. Goldstein. 1980. The estradiol-stimulated lipoprotein receptor of rat liver. A binding site that mediates the uptake of rat lipoproteins containing apoproteins B and E. J. Biol. Chem. 255:10464-10471.

47. Veldhuis, J. D., J. T. Gwynne, P. Azini, J. Garney, and D. Juchter. 1985. Estrogen regulates low density lipoprotein metabolism by cultured swine granulosa cells. Endocrinology. 117:1321-1327.

48. Eriksson, M. 1985. Estrogen and lipoprotein metabolism: increased catabolism of low density lipoproteins induced by pharmacological doses of estrogen in males. Eur. J. Clin. Invest. 15(Part II):360a. (Abstr.)

49. Jerome, W. G., and J. C. Lewis. 1984. Early atherogenesis in White Carneau pigeons. I. Leukocyte margination and endothelial alterations at the celiac bifurcation. Am. J. Pathol. 116:56-68.

50. Goldstein, J. L., and M. S. Brown. 1977. The low-density lipoprotein pathway and its relation to atherosclerosis. Annu. Rev. Biochem. 46:897-930.

51. Huber, L. A., E. Scheffler, T. Poll, R. Ziegler, and H. A. Dresel. 1990. 17-Beta-estradiol inhibits LDL oxidation and cholesteryl ester formation in cultured macrophages. Free Radical Res. Comm. 8:167-173. 